\title{
Age discrimination in mental health services needs to be understood
}

\author{
Dave Anderson ${ }^{1}$
}

The Psychiatrist (2011), 35, 1-4, doi: 10.1192/pb.bp.110.032094

${ }^{1}$ Mossley Hill Hospital, Liverpool, UK Correspondence to Dave Anderson (helen.bickerton@merseycare.nhs.uk)
Summary The ageing population presents a major challenge to health and social care services now and for decades to come. Age discrimination in mental health services is more pronounced than in other areas of healthcare. Legislation, currently being reviewed, which will make unjustified age discrimination unlawful from 2012, has implications for the organisation and delivery of mental healthcare that need to be understood.

Declaration of interest D.A. is the immediate past Chair of the Faculty of Old Age Psychiatry, Royal College of Psychiatrists, and member of the National Advisory Group on Age Discrimination in Health and Social Care. The opinions expressed in this editorial are his own and not necessarily those of these organisations.
In October 2009, the Royal College of Psychiatrists launched a position statement giving direction on the development of age-appropriate, non-discriminatory mental health services. ${ }^{1}$ The statement, describing how services should be based on need not age, was developed by a working group involving all faculties and sections of the College and was endorsed by the Royal College of General Practitioners, the Royal College of Nursing, the British Geriatrics Society, Age Concern and Help the Aged. Despite this important initiative, the principles of age-appropriate, non-discriminatory services still appear to be misunderstood by services and commissioners, in particular, the issues of indirect discrimination and age appropriateness. This is especially important for mental health services, which are among the most manifestly guilty of age discrimination within the National Health Service (NHS).

It is important to correct misunderstandings now for two reasons. First, the ageing population is the most important challenge facing the health and social care services now and for decades to come. ${ }^{2}$ It is predicted that the only increase in the number of people with any form of mental illness up to 2026 will occur by virtue of ageing. ${ }^{3}$ In this time, the number of people over age 85 will increase at a rate 6 times greater than the overall population growth, with a $54 \%$ increase in the number of older people with a high level of need. ${ }^{4}$ More than one commentator has described this global growth of the number of older people as a 'demographic tsunami'.

Second, age equality legislation, which is expected to be introduced in 2011, will make unjustified age discrimination in the UK unlawful from 2012.

\section{Age equality in UK legislation}

In 2008, the government announced the Equality Bill, now Act, which would prohibit unjustifiable discrimination on the grounds of age in goods, facilities, services and public functions. In 2009, at the request of the secretary of state for health and after public consultation, Sir Ian Carruthers and Jan Ormondroyd, supported by a national advisory group, produced a report to guide the implementation of this legislation in health and social care services. ${ }^{5}$

The Department of Health will produce written guidance for health and Social Services to help them prepare for legislation. ${ }^{6}$ An audit tool, with a specific section on mental health, is provided for organisations to evaluate their position as part of the preparedness measures. ${ }^{6}$ The public sector 'equality duty' is expected in 2011, adding age to the seven existing protected characteristics which will all be brought under one piece of legislation. In 2012, unjustifiable age discrimination will become unlawful.

The equality duty creates a public sector duty to have regard to the need to eliminate discrimination, as well as to advance equality of opportunity and foster good relations between people who share a protected characteristic and people who do not share it. The duty applies to eight protected characteristics, including age. The ban on age discrimination applies to people aged 18 or over, but the public sector duty applies to people of all ages, including children.

The Department of Health will consult on the subject of exceptions. These allow for specific situations in which it is permissible to treat people differently in relation to age to be written into secondary legislation. The other exception is the Statutory Authority to prevent conflict with other matters of statute.

The Equality Act will consider discrimination on the basis of age to be unlawful if it is not covered by an exception, the Statutory Authority, or if it fails to pass the objective justification test. This test requires demonstration that an action is a 'proportionate means' of achieving 
a 'legitimate aim', although neither proportionate nor legitimate are further defined. The expectation is that legal challenge will see this decided by the courts. The Act will allow for positive action that improves the situation of a group that is discriminated against.

\section{Is there age discrimination in mental health?}

There is now incontrovertible evidence that discrimination in mental health does exist. Anecdote suggests this has always been the case, but a report ${ }^{7}$ commissioned by the Department of Health not only confirmed the position, but quantified it in financial terms. It concluded that to provide older people with the same access to mental health services on the basis of equivalent need as that available to younger adults would cost approximately $£ 2$ billion per year, about one-seventh of the NHS mental health budget. A partner report ${ }^{8}$ found similar discrimination against older people in social care, of £0.5-2 billion per year. At least 14 reports in the past 5 years have confirmed discrimination, infringement of human rights, unmet need or neglect of older people. ${ }^{2}$ Most recently, in a description of the main areas of concern in mental health, older people were identified as one of the two most often mentioned groups in terms of inequalities, the other being Black and minority ethnic individuals. ${ }^{9}$ This last report makes mention of the exclusion of older people from many mental health services and of the poor and neglected fabric of older people's services.

\section{Age discrimination in mental health - how has it happened?}

In the present era, at least in England and Wales, the delivery of policy has been driven by National Service Frameworks. In 1999, the National Service Framework for Mental Health ${ }^{10}$ (NSFMH) brought much needed investment in mental health services, with the creation of new specialist teams and improvement in the delivery of treatment to people with mental illness. This was ringfenced new money, with commissioners directed to make these service changes to benefit people aged 18-65. Two years later, the National Service Framework for Older People $^{11}$ (NSFOP) was published and expected to address the needs of older people with mental illness. In fact, only one section (Standard 7) focused on mental illness and, then, only dementia and depression. For other conditions the NSFMH applied, although even this sequitur was never honoured.

Not only did the National Service Frameworks overtly favour younger adults and explicitly exclude older people, but, in the time between the two policies were produced, the implementation approach changed. In 1999, targeted service development with new money was accompanied by Department of Health-sponsored performance management, which ensured that commissioners and providers delivered the prescribed change. By 2001, the approach changed such that service development shifted to local prioritisation and so no targeted money came with the NSFOP where mental health was concerned.
This adopted approach of subsidiarity shifted decisionmaking to local commissioners and the force of national policy diminished. The standard mental health contract had little or nothing to say about older people's mental health and the drivers in the system left younger adults as the only mental health agenda item. This was compounded by the lack of sophistication in the commissioning process, with its inability to view the wider health and social care field or make necessary whole-system changes. Tackling the complex area of older people's mental health, which cuts across commissioning boundaries, was neither expected nor required. Change was made that would prove to disadvantage older people further.

In 2004, the national directors for mental health and older people acknowledged that older people had not benefitted from important developments for younger adults and called for this to be addressed. ${ }^{12,13}$ However, little has changed and, in relative terms at least, older people are substantially worse off now than they were 10 years ago. Not only are they excluded from investment and developments, but their increasing number is not matched by equivalent resource. A national survey of old age psychiatrists $^{14}$ indicated the failure of the NSFOP to produce change. A joint inspection report ${ }^{15}$ confirmed failure to make progress in mental health services for older people and with 12 months of its lifespan remaining, the NSFOP has yet to be delivered. ${ }^{16}$

It has been asserted that the existence of specialist mental health services for older people creates discrimination. ${ }^{17}$ But it was neglect of older people by single, ageinclusive, generic mental health services that led to the creation of old age psychiatry. Recognition of unmet need and the particular needs of older people has been evident since the $1940 \mathrm{~s},{ }^{18}$ yet old age psychiatry only became an NHS specialty in 1989. As Carruthers \& Ormondroyd state, ${ }^{5}$ the existence of older people's mental health services, of itself, is not discriminatory and could, in fact, be an example of positive action and support personalisation. It could be argued that if this separation had not existed, discrimination would have been more difficult to see.

Increasing age discrimination has been allowed to occur by inertia, the manner in which national policy has been framed, interpreted and commissioned, and an abject failure to respect and value older people. The policy approach in mental health has been overtly ageist. The professions and the NHS have colluded with that approach.

\section{What is age discrimination?}

The NSFOP declares that NHS services will be provided 'regardless of age, on the basis of need alone'. Provision of services based purely on the basis of need reflects the health equity concepts of horizontal equity (the equal treatment of equals) and vertical equity (the unequal, but fair, treatment of non-equals) that underlie two forms of discrimination, respectively direct and indirect discrimination. ${ }^{19}$

Direct discrimination occurs when a direct difference in treatment based on age cannot be justified. A direct difference in treatment is a situation in which a person is, was or could be treated in a less favourable manner than 
another person in a comparable situation based on that person's age.

Indirect discrimination occurs when a seemingly neutral provision, measure or practice has harmful repercussions for a person. It occurs when all age groups are treated the same without recognising different need of a particular age group, who are then disadvantaged. Indirect discrimination is harder to see and if mental health services do not understand it, discrimination will continue in a different but equally unacceptable guise, in the eyes of the law.

Age discrimination needs to be distinguished from age-differentiated behaviour, which is a well-thought out and justifiable difference in treatment by age based on a well-developed understanding of age differences. ${ }^{19}$ This is not discrimination, but action to prevent indirect discrimination.

The needs of different age groups can be considerably different and the skill set of staff working with older people may be very different from that needed by staff working with younger adults. ${ }^{20}$ This will have to be reflected in the way services are organised and delivered if they are to be considered non-discriminatory. It is clear that equity is not achieved by treating all people the same, but rather, equity recognises that different needs should be addressed differently but fairly. To treat all older people the same, or to treat all adults the same regardless of need are both discriminatory. The latter misguided response has become known as the 'chilling effect' or 'age-blind' approach, which is both incompatible with the legislation and cynical. So, how are older people's needs different?

\section{The population $\mathbf{v}$. individual conundrum}

In many ways, the issue we face is balancing the needs of large populations with the needs of individuals. By their very nature, services have to be developed with population needs in mind. Age is a proxy marker of need at a population level, but there is variation between individuals in any age group and some will not be typical of the larger group.

There is very good evidence for the proxy status of age in mental health. The epidemiology of mental illness shows different patterns of prevalence, the fundamental importance of life experience and lifestyle in psychiatry obviates the significance of understanding experience at different points in the life cycle. Physical health comorbidities characteristic of later life, cognitive disorders, sensory impairments, functional limitation, frailty, loss events, polypharmacy, susceptibility to adverse effects of drugs are all related to increasing age. ${ }^{2}$ These will all determine need.

Not only prevalence, but the nature and aetiology of mental disorders in later life, both cognitive and non-cognitive disorders, and their treatment are often significantly different. Both need and the delivery of services will be affected by these differences. ${ }^{2}$

Furthermore, because older people and those with multimorbidities tend to be excluded from research, ${ }^{21,22}$ treatment guidelines rarely take account of age-related differences. In consequence, guidelines like those of the National Institute for Health and Clinical Excellence may not be as applicable to older people as they are to other age groups. Where applicable guidelines do exist, treatment is relatively straightforward, but it is where there is absence of good evidence (typically the case with the older old) that the expertise of specialist practitioners, familiar working with a set of circumstances, is most important. ${ }^{2}$ Ensuring that practitioners have competencies in this context will be an important governance issue for the NHS. However, not all older people (however defined) will have these characteristics or needs, whereas some younger people may.

By and large, age has been used in mental health services as the single criterion that determines access to services. There is no single age that absolutely separates adults into discrete groups and so, logically, any single age criterion cannot be justified. However, to completely ignore age is as foolish and disrespectful as ignoring other protected characteristics of people, such as their gender, ethnicity, disability, sexual orientation or beliefs. People's characteristics matter. The particular difficulty with age is its being a continuous, not a dichotomous variable.

Some commentators link the problem of age discrimination with changing positions on retirement age, although these are only loosely connected. The common practice of designating people over age 65 as 'old' began in the 1880s, when Otto von Bismarck selected that age as the starting point for certain social welfare benefits, undoubtedly aware that few would live long enough to collect them and if they did, then not for long. But there has never been an age set up when all people had to retire and, until recently, the age at which women could collect a state pension in the UK was 60 , whereas for men it was 65 . A satisfactory definition of old is elusive, despite several competing concepts, but this need not concern us, for nobody doubts the reality of ageing and the existence of people in later life even without a precise definition, or that most people at certain points in the life cycle share characteristics in health and social care terms that determine need.

\section{Future mental health services}

The Department of Health's New Horizons initiative ${ }^{23}$ tries to correct some of the errors of past approaches. It is age-inclusive but pays attention to the particular needs of older people. It has been strongly influenced by the report of the Foresight Group, ${ }^{24}$ which emphasises the different needs of people at different points in the life cycle and explicitly recognises discrimination against the elderly as well as the need to plan for the evolving increased demands of an ageing population. New Horizons reaffirms treatment on the basis of need not age while adopting a life-cycle approach. It advocates creating fair access, while recognising that services must take account of the influence of age, referencing the importance of comprehensive specialist mental health services for older people in order to meet need across the life cycle. It confirms that services should be age-appropriate and that non-discrimination does not mean providing an identical service to all.

The Equality Act, New Horizons and other age-inclusive policies and guidance offer greater hope for a fair deal for older people. But they must be understood and implemented without cynicism. 
To deliver non-discriminatory, age-appropriate services on the ground will require mental health services to be much more sophisticated in the way they operate and the way specialties interact. Specialist services may respond well to a population need but they must not fail to meet the need of the individual. Services will need to fit patients and not vice versa. Age as a criterion is administratively neat and creates clear lines of accountability but needs-based services are more difficult to define and operate. Commissioners and providers will need to be very careful not to fall into the chilling effect trap that creates unacceptable indirect discrimination.

\section{Conclusion}

The solution to meeting the requirements of age-appropriate, non-discriminatory care cannot lie in treating all people in exactly the same way, nor can it mean replicating all services exactly the same for each age group. Indeed, it is the recognition that older people have different needs that is the essential indication for the need of different services.

The importance of age appropriateness for addressing discrimination is clear in the Carruthers \& Ormondroyd report, ${ }^{5}$ which states: 'every provider and commissioner of mental health services will need to consider how to achieve non-discriminatory, age-appropriate services' (p. 11). Further, the minister of health, Phil Hope, commented that it is 'the Government's broader aspiration to deliver high-quality care for all, including by means of more personalised, ageappropriate services'. ${ }^{25}$

Meeting the moral imperative and business need to respond more successfully to the needs of the ageing population will hinge on the development of comprehensive older people's mental health services, access to all services that would better meet a person's need regardless of age, patient choice and a more equitable distribution of resources. Older people's mental health services are 'the bedrock on which other services can rely' ${ }^{21}$ and, where evidence exists, prove more effective for older people than comparators. $^{2}$ Financial constraint and lack of resource is unlikely to be a defence for discrimination, rather, 'organisations will need to use service redesign to free up resources to provide better, more equitable, care' (p. 32). ${ }^{5}$

The Royal College of Psychiatrists' position statement ${ }^{1}$ and supporting evidence document ${ }^{2}$ give guidance on the defining competencies and expertise of older people's mental health services, their essential role in the fight against age discrimination and the steps that need to be taken to create fairer mental health service provision for older people. Will the NHS and professions now have the courage and honesty to address this serious injustice, which has been allowed to persist for over 60 years?

\section{About the author}

Dave Anderson is Consultant and Honorary Senior Lecturer in Old Age Psychiatry, Mossley Hill Hospital, Liverpool.

\section{References}

1 Royal College of Psychiatrists. Age Discrimination in Mental Health Services: Making Equality a Reality (Position Statement PS2/2009). Royal College of Psychiatrists, 2009.
2 Anderson D, Banerjee S, Barker A, Connelly P, Junaid O, Series $\mathrm{H}$, et al. The Need to Tackle Age Discrimination in Mental Health: A Compendium of Evidence. Royal College of Psychiatrists, 2009.

3 McCrone P, Dhanasiri S, Patel A, Knapp M, Lawton-Smith S. Paying the Price: The Cost of Mental Health Care in England to 2026. King's Fund, 2008.

4 Wanless D, Forder J, Fernandez J-L. Securing Good Care for Older People. King's Fund, 2006.

5 Carruthers I, Ormondroyd J. Achieving Age Equality in Health and Socia Care: A Report to the Secretary of State for Health. Central Office of Information, 2009

6 NHS South West. Age Equality in Health and Social Care - NHS South West Resource Pack. Department of Health, 2010 (http:// www.southwest.nhs.uk/age-equality.html).

7 Beecham J, Knapp M, Fernandez J-L, Huxley P, Mangalore R, McCrone P, et al. Age Discrimination in Mental Health Services. Personal Social Services Research Unit, 2008.

8 Forder J. The Costs of Addressing Age Discrimination in Social Care. Personal Social Services Research Unit, 2008.

9 Care Quality Commission. Position Statement and Action Plan for Mental Health 2010-2015. Care Quality Commission, 2010.

10 Department of Health. National Service Framework for Mental Health Modern Standards and Service Models. Department of Health, 1999.

11 Department of Health. National Service Framework for Older People. Department of Health, 2001

12 Appleby L. National Service Framework for Mental Health - Five Years On. Department of Health, 2004.

13 Philp I. Better Health in Old Age. Department of Health, 2004

14 Tucker S, Baldwin R, Hughes J, Benbow S, Barker A, Burns A, et al. Old age mental health services in England: implementing the National Service Framework for Older People. Int J Geriatr Psychiatry 2007; 22 211-7.

15 Healthcare Commission, Audit Commission, Commission for Social Care Inspection. Living Well in Later Life: A Review of Progress against the National Service Framework for Older People. Commission for Healthcare Audit and Inspection, 2006.

16 Healthcare Commission. Equality in Later Life: A National Study of Older People's Mental Health Services. Healthcare Commission, 2009.

17 Centre for Policy on Ageing. A Literature Review of the Likely Costs and Benefits of Legislation to Prohibit Age Discrimination in Health, Social Care and Mental Health Services and Definitions of Age Discrimination that might be Operationalised for Measurement. Centre for Policy on Ageing, 2007.

18 Hilton C. The clinical psychiatry of later life in Britain from 1950-1970: an overview. Int J Geriatr Psychiatry 2005; 20: 423-8.

19 Hagestad GO, Uhlenberg P. The social separation of old and young: a root of ageism. J Soc Issues 2005; 61: 343-60.

20 Department of Health, Care Services Improvement Partnership. Age Equality: What does it Mean for Older People's Mental Health Services? CSIP, 2007 (http://www.its-services.org.uk/silo/files/age-equalityguidance-note-pdf.pdf).

21 Fortin M, Soubhi $H$, Hudon C, Bayliss EA, van den Akker M. Multimorbidity's many challenges. BMJ 2007; 334: 1016-7.

22 Academy of Medical Sciences. Rejuvenating Ageing Research. Academy of Medical Sciences, 2009

23 Department of Health. New Horizons: A Shared Vision for Mental Health. Department of Health, 2009

24 Foresight Mental Capital and Wellbeing Project. Making the Most of Ourselves in the 21st Century: Final Project Report. Government Office for Science, 2008.

25 Hope P. Equality Bill: Age Discrimination in Health and Social Care Statement. Lords Hansard, Written Ministerial Statements 2009; 27 April (http://services.parliament.uk/hansard/Lords/ByDate/ 20090427/writtenministerialstatements/part002.html). 